\title{
O DESENVOLVIMENTO E A QUALIDADE DE VIDA NO CENTRO DA AGENDA ACTUAL - DUAS REALIDADES COMPLEMENTARES
}

\author{
Maria Olívia Dias ${ }^{1}$
}

\begin{abstract}
Resumo: As considerações que desenvolvemos neste artigo procuram conjugar os conceitos: desenvolvimento e qualidade de vida humana. Estes dois vocábulos ajudam-nos a perceber como estas duas realidades se envolvem e entrecruzam na vida prática das pessoas. Por conseguinte, estas linhas fazem uma reflexão a partir da qual será possível, mesmo com alguma subjectividade, até por vezes com realidades ambíguas, compreender de forma ajustada a complementaridade entre estes dois tópicos e a importância que têm o desenvolvimento e a qualidade de vida, tanto para as pessoas como para a sociedade.
\end{abstract}

Palavras-chave: Desenvolvimento, Qualidade de Vida, Pessoa, Realidade, Complementaridade, Problema Social

Abstract: The considerations developed in this article seek to combine the following concepts: development and quality of human life. These two concepts help us see how these two realities intersect and engage in everyday life. Therefore, these lines are a reflection from which is possible, even if with some subjectivity, sometimes even ambiguous realities, on an adjusted understanding of the complementarities of these two topics and their importance to the development and quality of life for both people and society.

Keywords: Development, Quality of Life, People, Reality, Complementary, Social Problem.

\footnotetext{
${ }^{1}$ Docente da Universidade Católica e colaboradora na Escola Superior de Enfermagem em Viseu. E-mail: profaoliviadias@gmail.com
} 


\section{INTRODUÇÃO}

Os objectivos não podem ser medidos através do balanço dos bancos. Eles só podem ser medidos através da qualidade de vida que proporcionam às pessoas

Lyndon Johnson cit. Fleck p.1

A par da tendência para o desenvolvimento ${ }^{1}$ tem-se verificado uma crescente preocupação com a qualidade de vida das pessoas sobretudo daquelas mais desprotegidas e mais carenciadas. Se nos reportarmos a um passado longínquo, verificamos que, actualmente, há melhorias significativas em relação a esses tempos, embora estes conceitos possam ter vários significados, em função de quem os avalia, o que os torna em certa medida bastante subjectivos, já que são avaliados não apenas numa perspectiva, mas, numa multiplicidade de factores que são vistos segundo aquilo que cada um espera deles para a melhoria das condições de vida tanto pessoais como sociais, que são diferentes, assim como o são os meios que os analisam: local, nacional, países ricos e pobres, desenvolvidos ou subdesenvolvidos (Lopes, ${ }^{5} 2001$ ).

Deste modo, o tema do desenvolvimento e da qualidade de vida assume a importância de um problema social particularmente no âmbito das ciências sociais, em geral, e em particular na Sociologia do Desenvolvimento e na Economia Social, áreas que nos colocam muitas interrogações e por isso acreditamos dar um contributo, ainda que muito simples, para uma melhor compreensão da relação entre os dois conceitos deste tema.

Percebe-se, então, como esta problemática não pode ser vista de forma micro mas macro-sociológica. Isto justifica-se por uma variedade de causas ou factores que a determinam e que são muitos e complexos.

Dito isto, buscar-se-á delinear nestas poucas linhas o conhecimento científico possível. Em primeiro lugar compreender as definições dos conceitos: desenvolvimento e qualidade de vida; num segundo momento analisaremos as relações que se estabelecem entre os dois conceitos desenvolvimento e qualidade de vida - mesmo com a própria subjectividade humana; para num terceiro e último ponto vermos como a manutenção de vida, o auto-respeito e a liberdade se cruzam com o desenvolvimento humano e a qualidade de vida das pessoas. 


\section{Os conceitos de desenvolvimento e de qualidade de vida}

Embora possa surgir alguma perplexidade em torno do entendimento sobre a aplicação concreta destes dois conceitos, nas sociedades de hoje, a questão tem suscitado grande importância, o que os torna cada vez mais actuais e actuantes na expectativa das pessoas.

Sem pretendermos discutir esta questão, de modo abstracto, lançamos neste breve texto, ainda que modestamente, um olhar sobre os aspectos do desenvolvimento e da qualidade de vida, no plano fenomenológico, com uma prevalência na orientação sociológica, reconhecendo a importância que têm noutras ciências como, por exemplo, a Biologia (aspectos físicos), Medicina (aspectos da saúde), Antropologia (aspectos culturais), Economia (aspectos económicos), Psicologia (relações comportamentais), Sociologia (aspectos sociais) e outras que se poderiam indicar. Praticamente toda a ciência, desde a Filosofia e a Teologia, ciências mais antigas, até às mais actuais, como é o caso da Sociologia, tratam estes conceitos dos pontos de vista de cada uma.

Sendo assim, as ideias ou as concepções que constituem estes dois termos - desenvolvimento e qualidade de vida - não esgotam o significado que estes encerram, pela complexidade que apresentam, pelas interpretações e análises diferentes que se podem fazer, pelo que devemos ter uma certa reserva no modo como os abordamos. Deste ponto de vista, faremos uma análise orientada para a acção do desenvolvimento humano na qualidade de vida das pessoas.

Estes dois conceitos, como nos apercebemos, são interdependentes e por isso têm tendência a actuar tanto no plano técnico como no plano moral. Mas, as definições, embora importantes, passam sempre por uma análise semântica e ao mesmo tempo linguística dos autores que as utilizam e caracterizam no seu conjunto.

Por conseguinte, não há uma definição única, cada ciência e cada autor que os define valoriza um ou outro aspecto, aquele que lhes é mais sensível. Porém, a ideia em relação ao conteúdo e à finalidade opera num sentido e significado que se torna mais ou menos comum e compreensível.

Ponderando a sua compreensão, dada a importância que estes termos têm, convirá introduzirmos algumas definições que sirvam para um melhor entendimento do seu conteúdo e do valor indiscutível que assumem na sua utilização prática. 


\subsection{O Desenvolvimento}

Se pegarmos em livros que tratem do conceito de desenvolvimento ou num dicionário, verificamos que este é descrito como o acto ou efeito de desenvolver. Assim, pode-se compreender a definição de desenvolvimento, que tem raiz no latim. Do desmembramento deste conceito temos (figura 1):

Figura 1

Desmembramento da palavra desenvolvimento

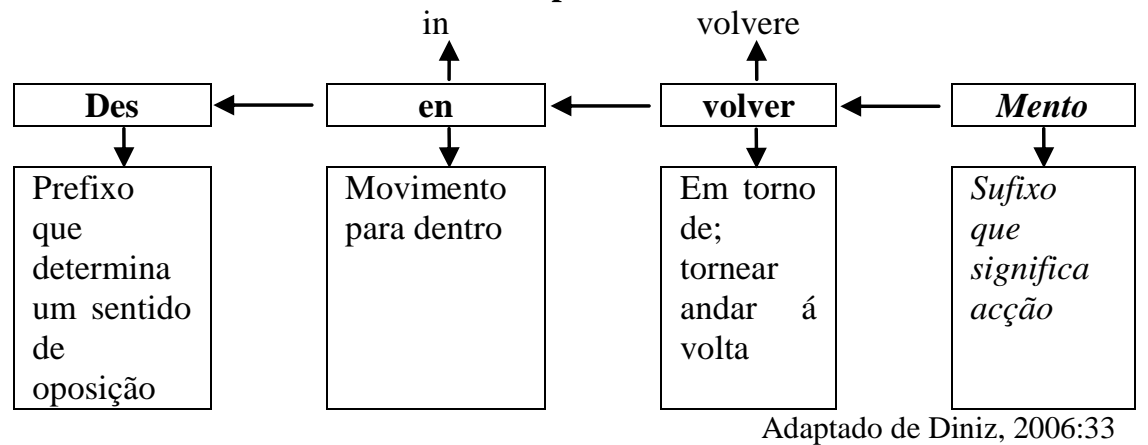

O vocábulo desenvolvimento é um conceito humano, associado à dimensão qualitativa e que se exprime no bem-estar e na qualidade de vida das pessoas. Portanto, o desenvolvimento privilegia o aspecto qualitativo com visibilidade no bem-estar físico, económico, psicológico, cultural, ético, religioso, políticas para a compreensão dos problemas, dificuldades e crises sociais (Perroux, 1981; Todaro, 1979; Rocher, ${ }^{3}$ 1980; Diniz, 2006).

Portanto, o desenvolvimento ${ }^{2}$ é entendido como sendo a combinação das mudanças mentais e sociais que tornam as pessoas aptas a fazer aumentar de modo cumulativo e durável as suas condições e o bem-estar pessoal e social (Perroux, 1981).

No entanto, o desenvolvimento confronta-se com um conjunto de desafios diversificados que, segundo Nunes (2001: 127 e ss.), requerem também a adopção de vias de desenvolvimento diferenciadas.

\subsection{A qualidade de vida}

O termo qualidade vem do latim qualitate e é utilizado em situações distintas. É um conceito subjectivo que está relacionado directamente com as percepções da pessoa. Implica diversos factores como cultura, 
modelos mentais, tipo de produto ou serviço prestado, necessidades e expectativas que influenciam directamente a definição.

Embora não haja um consenso a respeito do conceito de qualidade de vida, como já descrevemos supra, a Organização Mundial de Saúde (Fleck, 1998: 2,3) engloba três aspectos fundamentais referentes ao construto qualidade de vida 1) subjectividade, 2) multidimensionalidade 3) Presença de dimensões positivas (p. ex. mobilidade) e negativas (p. ex. a dor). A subjectividade está na percepção que o indivíduo tem da sua posição na vida, no contexto da cultura e sistema de valores nos quais ele vive, em relação aos seus objectivos, expectativas e preocupações. A multidimensionalidade reflecte-se nos diversos domínios, tais como: físico, psicológico, nível de independência, relações sociais, meio ambiente, religião, crenças pessoais, etc.

Questionamo-nos então, sobre o que é a qualidade de vida, que para Fausto Amaro (2006:143) pode desdobrar-se em várias dimensões, umas de natureza objectiva, outras de natureza subjectiva, sendo igualmente importantes. $\mathrm{O}$ autor indica as dimensões objectivas e subjectivas (figura 2):

\section{Figura 2}

Dimensões objectivas e subjectivas da qualidade de vida

\begin{tabular}{|c|c|}
\hline $\begin{array}{l}\text { Dime } \\
\text { Obje }\end{array}$ & $\begin{array}{l}\text { Dimensões } \\
\text { Subjectivas }\end{array}$ \\
\hline $\begin{array}{l}\text { Saúde física mental } \\
\text { Condições de habitação } \\
\text { Tipo de alimentação } \\
\text { Acesso a bens de consumo } \\
\text { essenciais } \\
\text { Acesso a bens culturais } \\
\text { Integração familiar e social } \\
\text { Acesso à participação cívica } \\
\text { Escolarização } \\
\text { Profissão } \\
\text { Rendimento suficiente }\end{array}$ & $\begin{array}{l}\text { Estas dizem respeito à forma } \\
\text { como } \\
\text { a pessoa avalia a sua qualidade } \\
\text { de vida podendo acontecer que a } \\
\text { avaliação subjectiva não } \\
\text { coincida em alguns casos com a } \\
\text { avaliação objectiva feita pelos } \\
\text { especialistas. } \\
\text { Isto porque se privilegia o } \\
\text { aspecto qualitativo em } \\
\text { detrimento do quantitativo. } \\
\text { É por isso que se privilegia o } \\
\text { bem-estar geral da população. }\end{array}$ \\
\hline
\end{tabular}

Esta questão da qualidade de vida não se coloca só a alguns, mas o problema é de todos, sentido por todos, seja ele mais objectivo ou subjectivo, o tema é sentido, entendido e interpretado por todos (Fonseca, 2006: 125), considerando-se um aspecto fundamental na análise destas 
condições, nomeadamente a satisfação com a vida e a própria qualidade de vida.

Este conceito foi partilhado por vários cientistas como já nos referimos. Para Fleck (1998:1), o facto do crescente desenvolvimento tecnológico da Medicina e ciências afins trouxe como uma consequência negativa a sua progressiva desumanização. Assim, a preocupação com o conceito de "qualidade de vida " refere-se a um movimento dentro das ciências humanas no sentido de valorizar o aumento das expectativas.

Foi assim que a expressão qualidade de vida foi empregue pela primeira vez pelo presidente dos Estados Unidos, Lyndon Johnson em 1964, ao referir: os objectivos não podem ser medidos através do balanço dos bancos. Eles só podem ser medidos através da qualidade de vida que proporcionam às pessoas (idem).

Portanto, do ponto de vista objectivo, a qualidade de vida integra diversas dimensões como qualidade para fazer face às despesas consideradas essenciais, qualidade do ambiente físico e social. Do ponto de vista subjectivo, a qualidade de vida é traduzida na avaliação que cada um de nós faz do conjunto de elementos que ele valoriza ou pode valorizar.

Sendo assim, a definição de qualidade de vida na sua multidimensionalidade resulta, como já citamos, do conjunto do ambiente físico, social, cultural, espiritual e económico, onde o indivíduo está inserido; estilo e acção que exerce sobre os outros, experiências vividas e expectativas futuras.

A qualidade de vida é assim mais geral e inclui uma variedade potencial maior de condições que podem afectar a saúde das pessoas, mas afecta também a percepção, os seus sentimentos e comportamentos relacionados com a vida diária do indivíduo.

Deste modo, o conceito de qualidade de vida é utilizado tanto no contexto da linguagem comum como no contexto das investigações científicas em diferentes áreas do saber: enfermagem, economia, psicologia, sociologia, educação, entre outras (Leal, 2008). Se transferirmos a noção de qualidade de vida para o contexto da bioética, verificamos uma forma de dignificação humana indispensável para a promoção da qualidade de vida e bem-estar das pessoas (Couvreur, 2001; Magalhães, 2001:222).

\section{A relação do desenvolvimento humano com a qualidade de vida}

Não entraremos em grandes detalhes e exploração de todo este fenómeno, que é o problema de desenvolvimento e da qualidade de vida para a população, não o levando até à exaustão, pois neste artigo apenas abordaremos alguns factores que são do nosso ponto de vista os que se 
manifestam como sendo aqueles que adquirem maior visibilidade e importância.

Como tema, procura incessantemente satisfazer as necessidades das pessoas, é esta realidade que lhe dá toda a originalidade e o torna de peculiar actualidade. Para haver qualidade de vida tem que haver uma dinâmica permanente do desenvolvimento, que tem de ser duradouro no espaço geográfico e no tempo.

Ao pretendermos focar um tema tão complexo, toda a dinâmica do desenvolvimento e qualidade de vida num artigo de poucas páginas, tínhamos consciência do risco de generalizar excessivamente o assunto, pelo que se optou por fazer apenas um estudo da relação entre estes dois conceitos, delimitando assim a sua análise.

Com isto, não pretendemos de modo algum menosprezar outros campos nesta área e que são igualmente importantes, apenas escolhemos estes por questão de interesse e actualidade. Embora delimitado, pode-se afirmar que o desenvolvimento consegue modificar e alterar a qualidade de vida do ser humano nas condições que favorecem o seu bem-estar geral. Esta análise circunstancial serve-nos como fio condutor na dinâmica que estes dois conceitos operam conjuntamente na vida das pessoas.

Durante muito anos, as investigações que vinham sendo feitas acerca desta problemática, desenvolveram-se dentro da Economia, ciência mais quantitativa, o que explica a ênfase colocada no crescimento e no progresso (Diniz, 2006: 32), ou seja, o produto interno bruto, o consumo, sectores de actividade, rendimento, etc. Só mais tarde sobretudo com a Sociologia do Desenvolvimento, e, em parte com a Economia Social, despertou o interesse por uma dinâmica e um processo de crescimento que passa por uma transformação que conduz a um estado qualitativo superior.

O desenvolvimento e a qualidade de vida são fenómenos dinâmicos que, embora traduzindo realidades que à primeira vista parecem diferentes, têm uma grande proximidade entre eles. $\mathrm{O}$ desenvolvimento trata de inverter a óptica habitual que põe no centro a produção e faz do homem um meio de produção, onde se sente insatisfeito. $O$ desenvolvimento tem em consideração a interligação de um maior conjunto de factores, como já anotámos acima, que têm em conta não apenas o crescimento económico, mas sim o crescimento da pessoa e da comunidade em todos os aspectos da sua vida.

Há uma sintonia entre estes dois conceitos, desenvolvimento e qualidade de vida. Podemos dizer que caminham de mãos dadas, até ao ponto em que o desenvolvimento entra nesta dinâmica estabelecendo relações fortes e estreitas de forma a elevar a capacidade de resposta a 
uma qualidade de vida mais adaptada a novas condições humanas e sociais. É por isso, que nós dizemos que o conceito de desenvolvimento integra o crescimento económico mas supera-o, porque presta atenção a tudo aquilo que contribui para a melhoria pessoal, social e cultural das populações. É seguramente um fenómeno multidimensional (Todaro, 1979: passim).

Precisamente, o crescimento compreende as modificações na evolução da sua ordem de grandeza, num período de referência. $\mathrm{O}$ desenvolvimento, engloba e ultrapassa o crescimento, implicando um conjunto de adaptações e, sobretudo, de transformações estruturais de carácter económico, social e cultural, sem as quais o crescimento se bloqueia. É por isso, que o desenvolvimento não se resume a um simples crescimento, é mais complexo ${ }^{3}$. É um processo essencialmente humano, associado à dimensão qualitativa e que se exprime no bem-estar geral da qualidade de vida das populações.

Um verdadeiro desenvolvimento é, pois, um fenómeno social e económico bastante complexo e multifacetado, integrando transformações de uma maneira geral nas sociedades, a criação de formas democráticas de produção, expansão e valorização da produção, a democratização das relações sociais, a eficaz concretização de uma política de plena dinamização para assegurar a satisfação das crescentes necessidades de toda a população por um lado, e de garantir a evolução equilibrada e harmónica do desenvolvimento da sociedade no seu conjunto, por outro (Abdelmalki \& Courlet, 1996: 41 e ss.).

Enquanto análise de bem-estar, esta relação é de natureza económica, social, cultural e política, propondo uma nova prática - uma prática centrada na mudança das condições que passa por múltiplos campos do bem-estar (Lopes, 1999: 1 e ss.). A qualidade de vida é, portanto, um objecto multidimensional do desenvolvimento social e humano que polariza um conjunto de realidades concretas, imediatas e quotidianas.

Podemos considerar, então, que existe uma relação muito estreita entre o desenvolvimento social, a economia e a qualidade de vida. Sem nos querermos alongar, no entanto, convirá assumir que a actual ordem económica internacional reclama uma nova ordem democrática internacional, ordem que não coloque em frustração o desenvolvimento dos países pobres, como tem acontecido, onde os ricos se tornam mais ricos com uma qualidade de vida invejável e os pobres cada vez mais pobres, sem os mínimos para viver mais ou menos dignamente.

Rosa Monteiro e Virgínia Ferreira (2010), citando Maria de Lurdes Pintassilgo, afirmam que os modelos de desenvolvimento impostos são pelos mais ricos sobre os mais pobres e por isso a consequente redução económica. As potencialidades de desenvolvimento da qualidade de vida são múltiplas. De facto, o desenvolvimento, numa perspectiva tanto 
nacional como internacional, contribui para a resolução de problemas concretos, desde os mais simples aos mais complexos, mobilizando sempre para um bem-estar melhor.

Por isso, a justiça de uma ordem económica internacional, nova e democrática é presentemente um dos factores importantes do desenvolvimento não só do crescimento económico, mas onde o social se impõe, baseado em princípios de igualdade e de equidade. A justiça permitirá assegurar o progresso de todos os países, em particular dos menos desenvolvidos, eliminando tantas desigualdades sociais, adoptando estratégias de desenvolvimento com conteúdos e mecanismos democráticos e satisfazendo interesses sociais nacionais e mundiais na sua globalidade, retribuindo o bem-estar (Galinha e Ribeiro, 2005: 1-4) às populações mais carenciadas e mais pobres, privadas do mínimo para sobreviver, dependentes de umas simples esmolas dos homens de boa vontade.

Infelizmente, na sociedade actual, a economia tornou-se um fim em si próprio, arrastada pelo progresso técnico (Diniz, 1982: 35), e arrastando, por sua vez, os povos para um crescimento indefinido como objectivo supremo, que leva a questionarmo-nos: Que género de desenvolvimento? Ao serviço de quem? Com que finalidade?

Impõe-se de certo modo a utilização de novos métodos de análise. È neste aspecto que a ciência sociológica, que não obtivera tanto êxito como a economia, pela facilidade que tem em controlar melhor as suas variáveis, poderá trazer a esta uma contribuição útil, ou seja, uma visão mais alargada do Homem e da Sociedade. Só deste modo se compreende a relação que não podemos descurar entre a ciência económica e o desenvolvimento social mais presente na ciência sociológica, que procura promover o Homem Todo e Todos os Homens, com influências sistémicas na qualidade de vida não só de alguns mas de todos.

Portanto, urge uma perspectiva de desenvolvimento humano que preconize estratégias centradas na ideia de crescimento em articulação com o social, ou seja, o desenvolvimento deve ser extensível aos vários domínios da vida social, como: saúde, alimentação, habitação, saneamento básico, educação, trabalho, meio ambiente, condições de melhor bem-estar não apenas material mas bem-estar global e a consequente qualidade de vida objectiva e subjectiva.

\section{Valores e condições para o desenvolvimento e qualidade de vida}

Neste contexto, poderíamos perguntar: será possível definir de modo geral e conceptualizar o que se pretende dizer quando falamos em desenvolvimento com elevação sustentada de uma sociedade, de uma 
comunidade, de um grupo, das pessoas no seu todo, de um sistema social orientado para uma vida melhor ou mais humana?

Das muitas componentes básicas, do nosso ponto de vista, pelo menos três são centrais e deveriam servir como base conceptual e de orientação prática para que se compreenda o significado que demos de desenvolvimento. Estes valores são fundamentalmente: a manutenção das condições de vida; o auto-respeito e a liberdade.

Os valores representam objectivos comuns, procurados por todos os indivíduos e pelas sociedades, como afirma Goulet (1981:87). Valores que se relacionam com as necessidades humanas fundamentais e que se manifestam em todas as épocas e em todas as culturas. Analisando estas três que escolhemos podemos então observar como se realizam.

\subsection{A manutenção das condições de vida}

A manutenção das condições de vida consiste na capacidade de prover as necessidades básicas da população. Todas as pessoas possuem estas necessidades, sem as quais a vida se tornaria impossível, e que incluem: a alimentação, habitação, saúde, água potável, protecção e segurança social, trabalho, educação, etc.

Quando alguma destas condições não está presente ou com uma oferta muito limitada, podemos afirmar, sem reservas, que existe uma condição de "subdesenvolvimento absoluto" e a pobreza das pessoas. Portanto, podemos dizer que o desenvolvimento económico e humano é condição necessária para a melhoria da qualidade de vida das pessoas (Giraud, 1998).

Sem um progresso económico sustentado e contínuo, o nível individual e social, a realização do potencial humano não será possível. É no âmbito do Programa das Nações Unidas para o Desenvolvimento (PNUD) que surge, no início dos anos 90, um novo conceito de desenvolvimento humano ${ }^{4}$. Este conceito vem definido como um processo, que permite o alargamento do leque de escolhas que são oferecidas para satisfazer as necessidades essenciais dos indivíduos, reconhecidas como direitos humanos, sobretudo dos mais carenciados. É, por isso, um conceito de desenvolvimento centrado nas pessoas, que tem em conta as necessidades descritas supra. Deste modo, o desenvolvimento humano é uma estratégia durável e sustentável no tempo, exigindo a eliminação da pobreza absoluta, diminuição das desigualdades tão presentes em todos os países mas tornando-se mais evidentes nos países mais pobres. É preciso um mundo mais solidário e humanizado (Nunes, et.al., 2001).

Portanto, o desenvolvimento social e humano é uma noção qualitativa que se exprime na qualidade de vida das pessoas. Assim, teremos de 
considerar os valores não só de ordem económica, mas também social e cultural, tendo em conta que uns afectam mais que outros certos grupos.

\subsection{O auto-respeito}

Os seres humanos são pessoas que se respeitam, há o sentido do valor que tem o respeito próprio, de não ser usado como instrumento pelos outros em benefício próprio. Todas as pessoas e sociedades buscam alguma forma de auto-respeito, ligado à autenticidade, identidade, dignidade, honra e reconhecimento.

A natureza e a forma do auto-respeito variam de sociedade para sociedade, de cultura para cultura, de pessoa para pessoa. No entanto, com a difusão dos valores modernizantes das nações desenvolvidas, muitos países pobres, que podem ter possuído um profundo sentido do seu próprio valor, passam a sofrer uma confusão cultural quando entram em contacto com sociedades avançadas. Isto porque a prosperidade e a qualidade de vida tornaram-se um valor e uma medida universal.

Devido à importância atribuída aos valores materiais das nações "desenvolvidas", confere-se hoje em dia, cada vez mais, um alto valor e respeito aos países que se desenvolveram e possuem riqueza. Para os mais pobres, desde que a estima e o respeito fossem conferidos com bases diferentes da realização material, seria possível resignarem-se à pobreza sem se sentirem desprezados. Por outro lado, uma vez que a imagem dominante de uma vida melhor inclui o bem-estar material como um dos elementos essenciais, torna-se difícil para os que são materialmente pobres sentirem-se respeitados ou estimados.

Por conseguinte, o desenvolvimento humano é legitimado como um objectivo porque é indispensável para se obter o respeito pelos mais pobres e pelas condições de vida que têm, respeitando-se a si próprios e aos outros.

\subsection{A liberdade}

A liberdade é ter autonomia para escolher. Enquanto todos não tiverem esta liberdade haverá sempre os que têm e os que não têm qualidade de vida. Mas, queríamos dizer que a liberdade não é aqui entendida num sentido político ou ideológico (por exemplo: "o mundo livre"), mas sim, num sentido fundamental de emancipação de condições materiais alienantes de vida, de servidão social, associada à ignorância, à miséria, às instituições e às crenças dogmáticas, à falta de direitos humanos (Mateus, et.al., 1995, passim). 
A liberdade envolve uma grande gama de escolha das sociedades e da sua população, assim como minimização das restrições externas na busca de um objectivo social que temos vindo a chamar "desenvolvimento humano" e "qualidade de vida".

Como dizia Lewis (s/d): 420) “...a vantagem do crescimento económico não está no facto de que a riqueza aumenta a felicidade, mas sim no facto de que ela aumenta a gama de escolha". Portanto, a riqueza pode tornar o homem capaz de obter maior controlo sobre a natureza e o meio (por exemplo: produção de alimentos, habitação, vestuário, etc.), do que se ele continuasse pobre. Fornece também a liberdade de escolher mais lazer, mais bens e serviços ou negar a importância dessas necessidades materiais e viver uma vida melhor.

Não nos surpreende que a chamada contracultura hippie do final dos anos 60 se desenvolvesse em grande parte entre jovens da classe média e da classe alta e rica dos países desenvolvidos.

Por outro lado, desenvolvimento humano é tanto uma realidade física como um estado de espírito, no qual a sociedade assegura através de certa combinação do processo económico, social e institucional os meios para obter uma vida melhor.

É por isso que, quaisquer que sejam as componentes específicas desta vida melhor, o desenvolvimento em todas as sociedades deveria ter objectivos mínimos, tais como: a) aumentar a disponibilidade e ampliar a distribuição de bens essenciais para a manutenção de vida, tal como os alimentos, abrigo, saúde, protecção, de modo a alcançar todas as pessoas da sociedade; b) elevar os níveis de vida, incluindo além de rendimentos mais altos a oferta de empregos, melhor educação e mais atenção aos valores culturais e humanistas (Dias e Ferreira: 2005). Tudo isso serve não só para aumentar o bem-estar material mas também para gerar maior auto-respeito individual e nacional; c) expandir a gama de escolha económica e social dos indivíduos e nações, libertando-se da servidão e da dependência não apenas em relação a outras pessoas, mas também em relação às forças da ignorância e miséria humana.

\section{Considerações finais}

Poderíamos, nesta parte final, interrogarmo-nos sobre três questões: a) Será que os níveis de vida em geral se expandiram dentro de uma nação a ponto de melhorar a pobreza absoluta (isto é a privação de bens de manutenção de vida), o grau de desigualdade na distribuição da riqueza, o nível de emprego, a natureza e a qualidade dos serviços da educação, da saúde e outros serviços sociais e culturais? b) Será que o processo económico aumentou o respeito individual e de grupo, tanto interno como externo, entre regiões? c) Será que o processo económico expandiu o 
leque de escolha humana libertando as pessoas da dependência externa e da servidão interna, ou meramente substitui uma forma de dependência económica, esquecendo as políticas sociais e culturais para uma melhor qualidade de vida?

Se a resposta para cada uma destas três perguntas for "sim" então significa que há um verdadeiro desenvolvimento e pode-se dizer que na nação na qual estes fenómenos ocorreram é inquestionável o desenvolvimento humano. Deixamos à consideração dos que lerem este artigo.

Mas, este desenvolvimento humano é também, como dissemos, um processo multidimensional que envolve mudanças nas estruturas, nos valores e nas instituições, bem como na aceleração do crescimento económico, a redução da desigualdade e a erradicação da pobreza. Essencialmente o desenvolvimento humano deve representar uma completa gama de mudanças pelas quais o sistema social, adaptado às diversas necessidades básicas dos grupos sociais e das pessoas dentro deste sistema, afasta-se de uma condição de vida percebida amplamente como insatisfatória, na direcção de uma condição de vida considerada "melhor" material e espiritualmente.

Constatamos que os países pobres defrontam-se ainda com muitos problemas de ordem global, baixos níveis de vida, bens insuficientes, condições de saúde inadequadas, serviços educacionais e outros serviços deficientes e muito limitados, dependência, baixa produtividade, baixo auto-respeito na sua identidade, dignidade, respeito, honra, reconhecimento, baixa motivação, liberdade limitada, pouca liberdade nas escolhas tais como: ganhos materiais, lazer, beleza, estilos de vida, controlo do próprio destino, ser dominado e independente.

Não obstante todo este reconhecimento pela insatisfação de bens essenciais os países ainda não conseguiram responder ao desenvolvimento humano e proporcionar às pessoas uma qualidade de vida que é desejada por todos.

A qualidade de vida não depende só da saúde, de bens materiais, depende muito da personalidade de cada um. Não é só a percepção que o indivíduo tem da sua posição na vida, no contexto da cultura e do sistema de valores nos quais vive e em relação com os seus objectivos e expectativas.

Em suma, haverá que cuidar das assimetrias, combater as desigualdades entre as pessoas, através de políticas económicas e sociais, é sendo preciso criar planos de desenvolvimento que combatam as diferenças para que tenhamos uma qualidade de vida melhor para todos ${ }^{5}$. 


\section{NOTAS}

1) É especialmente desde o fim da II Guerra Mundial que se fala cada vez mais do desenvolvimento. A partir daqui escreveu-se muito sobre o desenvolvimento, cobrindo um campo mais vasto e mais complexo do que o crescimento económico.

2) $\mathrm{Na}$ perspectiva clássica o desenvolvimento confunde-se com o crescimento económico, que pode ser definido como o incremento duradouro de uma unidade económica, simples e complexa, realizado nas mudanças e nas estruturas (e eventualmente de em sistemas), acompanhado de progressos económicos. Diligencia-se principalmente o impacte do desenvolvimento sobre a condição humana (Darling, 1971, apud, Gazeneuve Jean e Victoroff, David, 1982: 258-259).

3) As diferenças de desenvolvimento entre os diferentes países do mundo sempre constituíram um grande problema, acentuado-a partir da Revolução Industrial. Alguns países assistiram a grandes transformações e a um progresso económico sem precedentes, que permitiu melhorar significativamente as condições económicas, sociais e culturais benefícios económicos que trouxeram benefícios sociais e culturais. Como os países subdesenvolvidos não conseguiram progressos, não tiveram repercussões no domínio social e cultural, daí a necessidade de distinção do conceito de crescimento e desenvolvimento. É por isso que a noção de crescimento está associada à dimensão quantitativa e o desenvolvimento a uma dimensão qualitativa.

4) Daí para cá todos os anos sai o Relatório do Desenvolvimento Humano, que em cada ano se ocupa dos temas mais actuais relacionados com o conceito de desenvolvimento. São publicados a nível nacional e internacional e são um dos melhores documentos para a análise comparativa entre os diferentes países do mundo em relação ao desenvolvimento humano nos diálogos com a política.

5) Algumas repetições ao longo deste texto, que acrescentam sempre algo, não foram deixadas ao acaso, têm principalmente como objectivo relevar e acentuar, conduzindo a análise de modo a que se tornasse cada vez mais pertinente à medida que ia sendo desenvolvida pela importância da relação entre desenvolvimento e qualidade de vida nos factores que os caracterizam. 


\section{REFERÊNCIAS BIBLIOGRÁFICAS}

ABDDELMALKI, Lahsen e COURLEL; Claude (1996) - Les Nouvelles Logiques du Développement - Globalisation versus Localisation, Paris: Éditions L`Harmattan.

AMARO, R. (1990) - Caminhos de desenvolvimento para a Beira Interior, 10 interrogações, Fundão: III Jornadas da Beira Interior.

AMARO, Fausto (2006) - Introdução à Sociologia da Família, Lisboa: Instituto Superior de Ciências Sociais e Políticas.

ASSOCIAÇÃO Portuguesa de Sociologia (1993) - Dinâmicas culturais, cidadania e desenvolvimento local, Actas do Encontro realizado em Vila do Conde promovido pela Associação Portuguesa de Sociologia.

BOUDON, Raymond (1984) - La place di désordre: critique des théories du changement social, Paris: PUF.

COUVREUR; C.H. (2001) - A qualidade de vida - Arte para viver no séc. XXI, Loures: Lusociência-Edições técnicas e científicas.

DAVID, E. Apter (1970) - "Sviluppo, modernizzazione e industrializzazione" in Antologia di Scienza política, Bologna:Il Mulino.

DIAS, Maria Olívia \& FERREIRA; Maria Manuela (2005) - Ética $e$ profissão-Relacionamento interpessoal, Loures: Lusociência

DINIZ, Francisco (2006) - Crescimento e desenvolvimento económico Modelos e agentes do processo, Lisboa: Edições Sílabo.

FEYTOR PINTO; Vitor (1996) - "Humanização e qualidade de vida" in Servir vol. 44, nº 1 p.12-20.

FONSECA, António Manuel (2006) - Desenvolvimento humano, Lisboa: Climepsi Editores.

FLECK, Marcelo Pio de Almeida (org.), (1998) - Avaliação da qualidade de vida (Whool) [online]. [citado a 3 de Novembro de 2010], p.1-7, Disponível na World Wide Web: <http://www.ufrgs.br/psi/wholl.html>.

GALINHA, Iolanda \& RIBEIRO; J. L. Pais (2005) - "História e evolução do conceito de bem-estar subjectivo", Psico., Saúde \& doenças [online]. Nov.vol.6 $\mathrm{n}^{\mathrm{o}} 2$ [citado a 3 de Novembro de 2010], p.203,204, Disponível World Wide Web: http://www.Scielo.oces.mctes.pt.

GAZENEUVE; Jean \& VICTOROFF, David (dir) ( $\left.{ }^{2} 1982\right)$ - Dicionário de Sociologia, Lisboa/São Paulo: Verbo.

GIDDENS, Anthony (1992) - As consequências da modernidade, Oeiras: Celta. 
GIRAUD, Pierre Noel (1998) - A desigualdade no mundo - a economia do mundo contemporâneo, Lisboa: Terramar.

GOULET, Denis (1981) - The cruel choise: A new concept in theory of development, Nova York: Atheneum.

INGLEHART, Ronald (2001) - Modernización y posmodernización. El cambio cultural economic y político em 43 sociedades, Madrid: CIS.

LANDES; David (2001) - A riqueza e a pobreza das nações: porque são algumas tão ricas e outras tão pobres, Lisboa: Gradiva.

LEWIS, W. Arthur (s/d) - Is economic Growth desiderable? In theory of ecomonic growth.

LEAL, Carla Manuela da Silva (2008) - Reavaliar o conceito de qualidade de vida, Brasil. Recuperado a 3 de Novembro de 2010.

LOPES, António Mendes (1999) - Qualidade de vida - uma problemática do desenvolvimento da sociedade [online]. (citado a 3 de Novembro de 2010), Disponível na World Wide Web: <http://www.apagina.pt.>.

LOPES, António Simões ( $\left.{ }^{5} 2001\right)$ - Desenvolvimento regional, Lisboa: Fundação Calouste Gulbenkian.

MAGALHÂES, V.P: (2001) - "Qualidade de vida" in Novos desafios à bioética, Porto: Porto Editora.

MARQUES, Alfredo (1988) - Política económica e desenvolvimento em Portugal, Lisboa: Livros Horizonte, Lda.

MATEUS, Augusto, BRITO, Brandão \& MARTINS Victor (1995) Portugal XXI - Cenários de desenvolvimento, Lisboa: Bertrand, Lda.

MONTEIRO, Rosa \& FERREIRA Virgínia (s/d) Desenvolvimento e qualidade de vida [online]. (citado a 4 de Novembro de 2010), Disponível na World Wide Web: <http://www.arquivopintasilgo.pt.

MURTEIRA; Mário (s/d) - Desenvolvimento, subdesenvolvimento e o modelo português, Lisboa: Presença.

NUNES, Francisco, RETO, Luís \& CARNEIRO, Miguel (2001) - O terceiro sector em Portugal: Delimitação, caracterização $e$ potencialidades, Lisboa: INSCOOP.

ORGANIZAÇÃO das Nações Unidas (1994) - Terres vivres et population, Roma: FAO.

PIERRE, Ralle e GUELLEC, Dominique (2001) - As novas teorias do crescimento, Barcelos: Civilização editora.

PERROUX, François (1981) - A filosofia do novo desenvolvimento, Lisboa: Fundação Calouste Gulbenkian.

ROCHER, Guy ( $\left.{ }^{3} 1980\right)$ - Sociologia geral, Lisboa: Editorial Presença.

SILVA, Manuela (org.) (1985) - Políticas de desenvolvimento económico e social, Lisboa: IED. 
TODARO, M. (1979) - Introdução à economia: uma visão para o terceiro mundo, Rio de Janeiro: Campus. 